\title{
Input switched closed-loop single phase SEPIC controlled rectifier with improved performances
}

\author{
Md. Shamsul Arifin, Mohammad Jahangir Alam
}

Department of Electrical and Electronic Engineering, Bangladesh University of Engineering and Technology, Bangladesh

\begin{tabular}{l}
\hline \hline Article Info \\
\hline Article history: \\
Received Apr 11, 2020 \\
Revised Jun 18, 2020 \\
Accepted Aug 3, 2020 \\
\hline
\end{tabular}

\section{Keywords:}

DC-DC converter

Feedback circuit

SEPIC controlled rectifier

Total harmonic distortion (THD)

\begin{abstract}
DC power supply has become the driving source for some essential modern applications. Thereby, DC power conditioning has become a significant issue for engineers. Typically used rectifiers associated with a bridge structure is nonlinear in nature. Thereby, the current at input side of the rectifier contains harmonics, which also flow through the power line. The presence of harmonics causes several interruptions and reduce power quality. In this regard, a new close loop SEPIC controlled rectifier is proposed in this paper. The conventional scheme is arranged with a rectifier connected to a DC-DC converter, which is an open loop system. Consequently, such system cannot regulate voltage at load varying condition. The proposed SEPIC controlled rectifier can regulate voltage under load varying condition for a wide range. Additionally, the performance in terms of total harmonic distortion (THD) of input current and power factor at AC side are also within satisfactory range for the closed loop configuration. The controlled rectifier has four operating phases associated with switching states and input voltage polarity. The close loop configuration also incorporates a current and a voltage loop at the feedback path. The comparative studies have been performed among the proposed closed loop construction, the open-loop structure as well as the conventional construction. The effectiveness of the proposed controlled rectifier is verified in terms of THD and input power factor considering the results obtained from simulation.
\end{abstract}

This is an open access article under the CC BY-SA license.

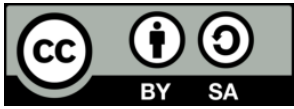

\section{Corresponding Author:}

Md. Shamsul Arifin,

Department of Electrical and Electronic Engineering,

Bangladesh University of Engineering and Technology,

Ramna, Dhaka, Bangladesh.

Email: msarifin@mun.ca

\section{INTRODUCTION}

The computer and telecom industries are growing rapidly in modern world. Moreover, electric vehicles are becoming the pioneer in modern transportation sector as the conventioal engine driven vehicles introduce environmental pollution. DC power supply is the driving force for these sectors. Consequently, the demand of DC power supply is increasing at present situation. Furthermore, the DC generation also plays a vital role in the control sectors of power plants, renewable energy systems as well as in aviation sectors all over the world. Both the military and civil aircrafts also incorporate a huge application driven by DC power supply [1-4]. Generally, rectifiers are used to supply the direct (DC) power in various applications discussed above. These rectifiers take alternating (AC) supply as input, for which the input current of these rectifiers is also alternating and contains huge harmonics [5-8]. For the presence of harmonics, the shape of input current becomes non-sinusoidal. This non-sinusoidal current introduces number of problems and non-idealities in grid system. some common problems are the power loss for the presence of harmonics, core saturation effect 
visible in electric machines etc. As a result, harmonic contents in power supply has become a serious challenge in industrial as well as power system engineering. Hence developing different methods for harmonic reduction is a prominent research area in the field of power electronics [5-7, 9-10].

There are different methods to separate the harmonics from main power signal. Active and passive filtering methods are mostly used among different methods. The passive filter introduces bulky inductors and capacitors, which are costly and less flexible. Alternatively, the active filtering technique incorporates high frequency switching arrangements, for which the size of filter capacitor and inductor has been reduced [10-15]. Consequently, active filtering technique has achieved its acceptancy among researchers as well as industrial engineers.

The common configuration of AC-DC converter consists of an uncontrolled rectifier connected to a DC-DC converter of different topologies at output end. For these types of configuration switching is performed at DC side of the rectifier. However, in recent years several new circuits are designed and investigated based on input side switching [5-7, 10, 12, 15-17]. These circuits are capable to convert alternating power to direct power with maintaining satisfactory distortion in current and power factor at input side. But these circuits are unable to maintain constant output voltage and satisfactory performance under different load condition due to having no feedback system [5-7, 10, 12, 15-17]. In the best of the authors' knowledge, very few researches has been performed based on controlled rectifier with feedback system, i.e. closed loop configuration.

Recently, several works have been performed to separate the harmonics from input current of the AC-DC converter as well as from line of the grid. In order to seperate the hartmonics and keep the total harmonic distortion (THD) and power factor at satisfactory level, the multistage converter having 6, 12 or 24 pulse system is widely investigated [18-21]. However, it is difficult to produce synchronized pulses, thereby the control system becomes more complicated for the multistage converter. On the contrary, some researches incorporate matrix converters, which is also challenging to implement and control as a number of switching devices are associated [22-24]. However, in both cases the switching loss increases, which affects the overall efficiency of the converters [25]. Among a number of recent researches, some significant works introduces automatic-power-decoupling controlled rectifiers, quad-active-bridge AC-DC converter, multi-level packed U-cell converter, converter associated with reference current generation schemes based on artificial intelligence etc [26-30]. However, it is challenging to implement and control these schemes as technical complexities are associated with the schemes.

In this regard, a close loop SEPIC controlled rectifier is investigated in this paper. The SEPIC topology has some vital advantages over other conventional topologies. SEPIC topology contains less active comonents compared to ĈUK structure. However, the major benefits incorporate its low noise operation and robust control scheme. Additionally, it is used reliably in renewable energy sector instead of ĈUK converter due to having less power ripple and stability of operation [5]. This proposed controlled rectifier has four operating phases, each of which are associated with the high frequency chopping of input AC current $[5,10]$. Additionally, the current and voltage loops ensure regulated voltage at output with better performances.

This paper is structured as follows. The typical construction and operation of the current and voltage loops are described in section 2. Furthermore, the construction of the poropsed closed loop SEPIC controlled rectifier is illustrated in section 3. Section 4 explains about the operational phases of the controlled rectifier. Section 5 represents the simulation results and analytical discussion. At the end, a conclusion is drawn in section 6 .

\section{THE CONSTRUCTION OF CURRENT AND VOLTAGE LOOPS}

The feedback circuit of the system incorporates a current loop as well as a voltage loop. Figure 1 illustrates the commonly used structure of both current and voltage loops. The voltage loop produces an error signal comparing the reference voltage and output voltage sample. The sample voltage is collected with the help of a voltage sensor. Furthermore, the produced error signal is then processed passing through a PI controller. This controller helps to smooth the error signal and this modified error signal is then goes to the input of a multiplier. This signal is multiplied with the input voltage sample and this product acts as the input for current loop. This product is further compared with the sample input current in the current loop and a current error signal is generated. Furthermore, this signal is passed through another PI controller. The signal achieved from the controller acts as the final reference signal for the system. This reference is then compared with a carrier signal of appropriate frequency. A gate pulse of convenient duty cycle is thus created for load varying situation. The pulse is given to the gate terminal of switching device $[6,31,32]$. 


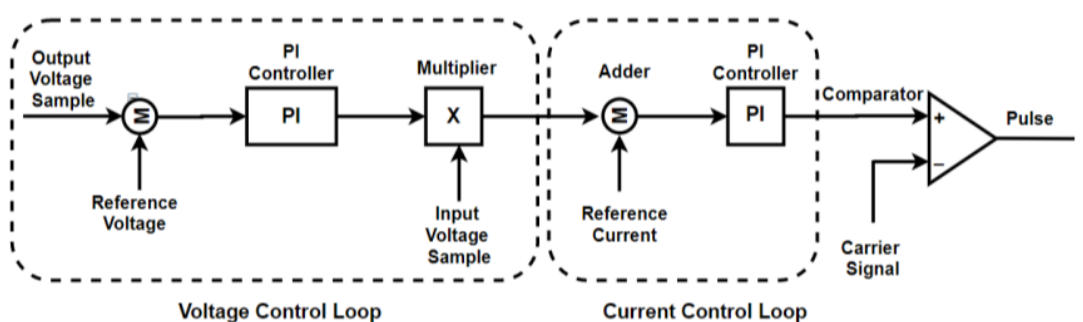

Figure 1. The construction of the current and voltage loops

\section{CONSTRUCTION OF PROPOSED CIRCUIT}

Figure 2 represents construction of the proposed closed loop SEPIC controlled rectifier. The converter is constructed with two capacitors $(\mathrm{Cl}, \mathrm{C} 2)$, four inductors ( $\mathrm{L} 1, \mathrm{~L} 2$, L3 and L4), a switching device (Ml) and several diodes. The inductors $\mathrm{Ll}, \mathrm{L} 2$ and the capacitor $\mathrm{Cl}$ transfer energy at positive half cycle of the power supply. Similarly, the L3, L4 and C2 are associated with the negative half cycle. However, the inductors indicated as L_Pos, L_Neg and the capacitors C_Pos, C_Neg have the function of filtering at input side. The capacitor $\mathrm{C}_{-}$Load acts as output capacitor and has the function of removing ripple from output voltage and R_Load is load of the system. Furthermore, the feedback system contains the current and voltage loops. The voltage loop is used to keep the output voltage constant as well as the current loop asists to keep high power factor at input side by providing a pulse of appropriate duty cycle at the switching device (M1).

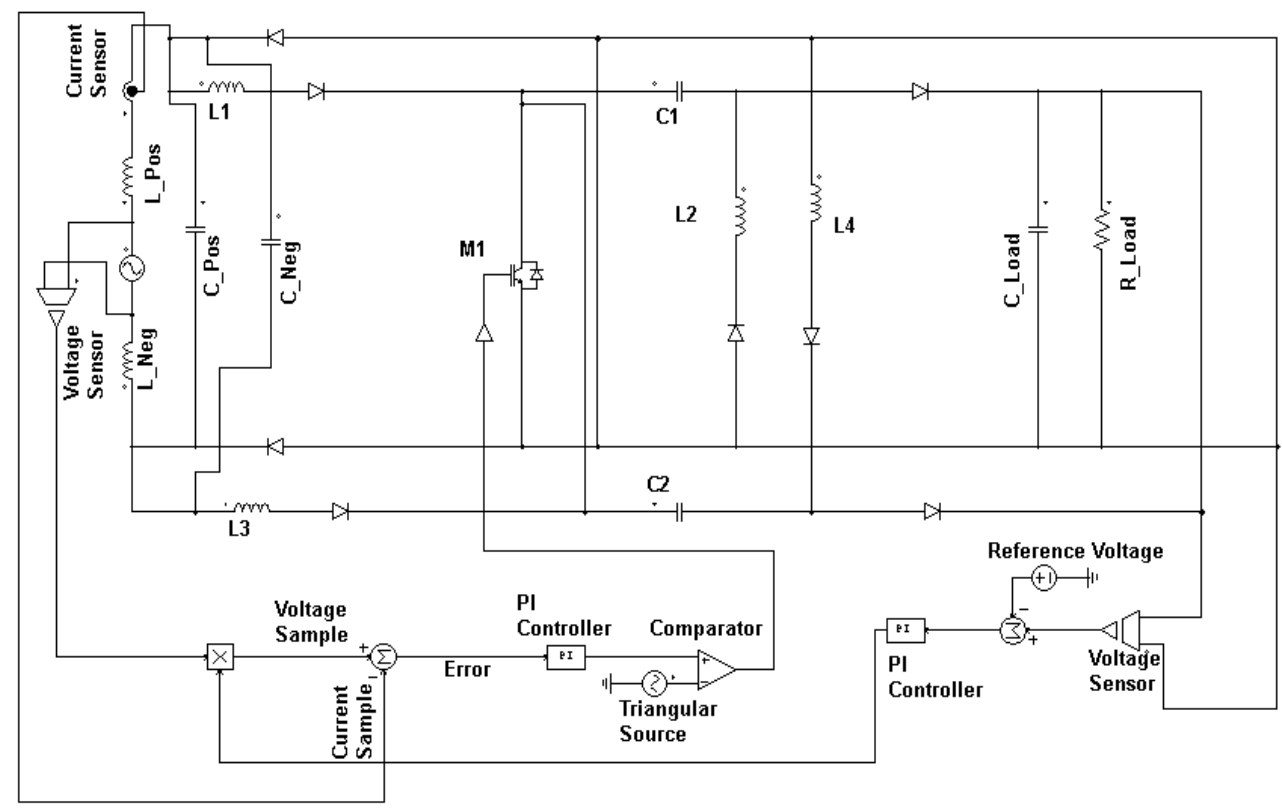

Figure 2. Construction of proposed SEPIC controlled rectifier

\section{PHASES OF OPERATION}

In the controlled rectifier proposed here, the input AC current is chopped using high frequency switching device. As a result, the size of filter components reduces significantly. Furthermore, high frequency switching at input side also reduces the THD as well as keeps the power factor at satisfactory level. However, the proposed controlled rectifier has four operating phases which are illustrated in Figure 3. Phase 1 and phase 2 as indicated in figure are associated with positive period of the total cycle and the switching states of $\mathrm{ON}$ and OFF respectively. On the other hand, phase 3 and phase 4 illustrates the operating phases for negative period and the switching states of $\mathrm{ON}$ and OFF respectively. The inductors L1, L2 and the capacitor C1 participates at energy transfer in positive period, which are indicated as phase 1 and phase 2. Similarly, inductors L3, L4 and the capacitor C2 are associated with phase 3 and phase 4. 


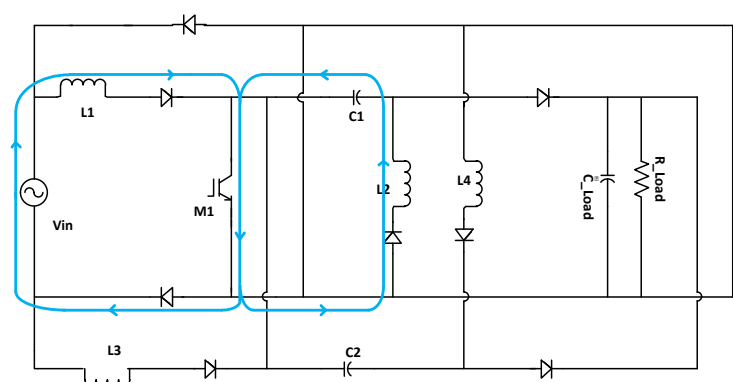

(a)

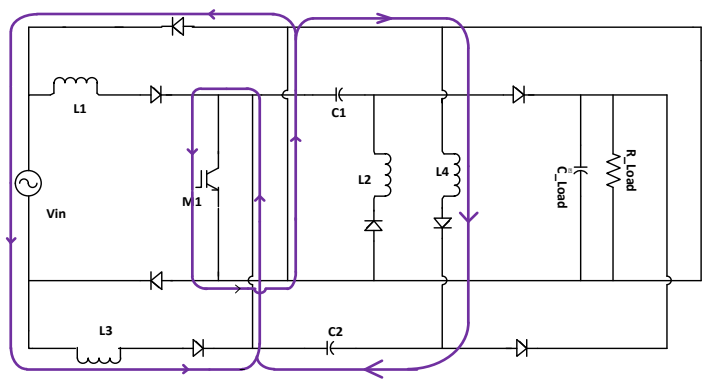

(c)

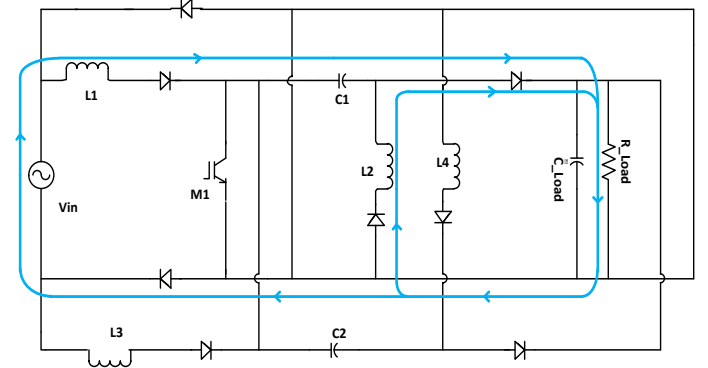

(b)

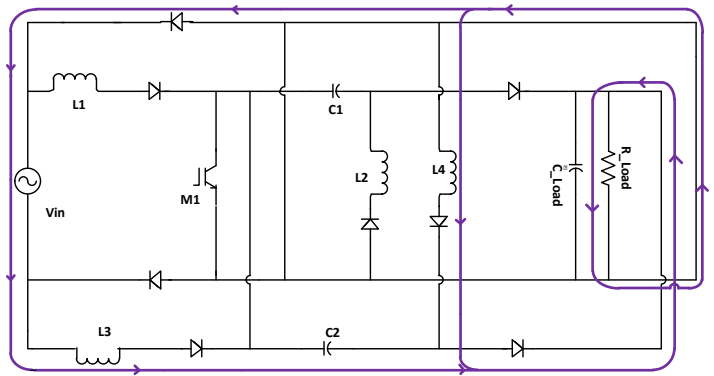

(d)

Figure 3. The operating phases of the proposed SEPIC controlled rectifier, (a) Phase 1, the positive period of the cycle and the switch is ON, (b) Phase 2, the positive period of the cycle and the switch is OFF, (c) Phase 3, the negative period of the cycle and the switch is ON,

(d) Phase 4, the negative period of the cycle and the switch is OFF [5]

\section{SIMULATION RESULTS AND DISCUSSIONS}

\subsection{Circuit parameters}

The SEPIC controlled rectifier is simulated with the help of PSIM professional version 9.0.3.400. A sinusoidal supply source having $300 \mathrm{~V}$ peak and $50 \mathrm{~Hz}$ frequency is selected for the simulation. For the switching mechanism, an insulated gate bipolar transistor (IGBT) is selected. For the SEPIC controlled rectifier, the inductors (L1 and L3) associated with energy transfer have the value of $1 \mathrm{mH}$ each. Additionally, the inductors (L2 and L4) have the value of $2 \mathrm{mH}$ each. Furthermore, the capacitiors (C1 and $\mathrm{C} 2$ ) having the function of energy transfer have the value of $1 \mu \mathrm{F}$ each. On the contrary, the inductors (L_Pos and L_Neg) and the capacitors (C_Pos and C_Neg) have their values of $15 \mathrm{mH}$ and 2 $\mu \mathrm{F}$ each, respectively. The output capacitor (C_Load) used for removing ripple from output voltage has the value of $470 \mu \mathrm{F}$ and the value of load is changed to investigate the performance of the proposed SEPIC controlled rectifier. However, the load considered for the study is resistive in nature. The proposed close loop structure is compared with an open loop structure of same controlled rectifier as well as with conventional AC-DC converter having SEPIC DC-DC converter at output end.

\subsection{Results and discussions}

The waveshapes of AC side current $\left(\mathrm{I}_{\mathrm{in}}\right)$ and voltage at output terminal $\left(\mathrm{V}_{\mathrm{o}}\right)$ of the proposed controlled rectifier, achieved from simulation are shown in Figures 4-6. The sampling frequency of the switching device $\left(\mathrm{f}_{\mathrm{s}}\right)$ is selected as $4 \mathrm{KHz}$. Considering the waveforms, it is evident that, for the proposed close loop SEPIC controlled rectifier the AC side current is approximately sinusoidal in shape. Additionally, the output voltage is also regulated at load varying condition. Figures 7-9 represent the spectrum of AC current $\left(I_{i n}\right)$ for the controlled rectifier. It is also obvious from the spectrum that $I_{i n}$ is nearly sinusoidal which is reflected by the presence of large peak at $50 \mathrm{~Hz}$ in the spectrum.

The numerical results considering the THD of alternating current as well as the power factor of proposed controlled rectifier are presented in Table 1. An extensive range of load resistance (50 $\Omega$ to $500 \Omega$ ) is considered while the numerical results are achieved. As per the given standard of IEC 61000-3-2 and IEC 61000-3-4, for any AC-DC converter the input current THD will be acceptable upto 10\% considering the fundamental frequency component. Considering the numerical results as illustrated in Table 1 , it is obvious that the values of THD are within acceptable range for all the load values. The value of THD is 
below $10 \%$ for all the load. Above $200 \Omega$ the THD is always less than $8 \%$. Similarly, observing the table we can also summarize that the power factor of the proposed SEPIC controlled rectifier is very high for all the load values. For most of the cases, the power factor is above $98 \%$.
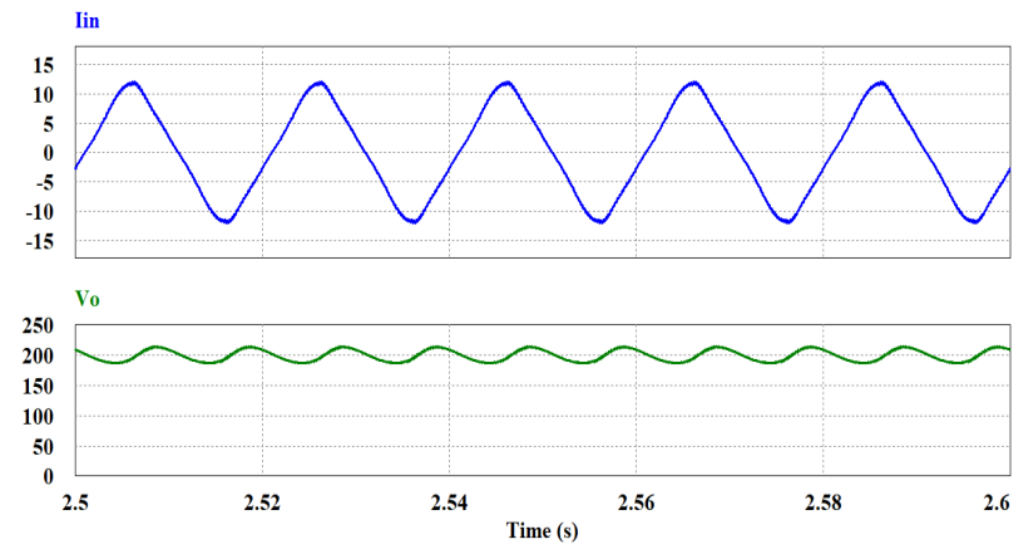

Figure 4. Waveshape of the input current $\left(\mathrm{I}_{\mathrm{in}}\right)$ and the output voltage $\left(\mathrm{V}_{\mathrm{o}}\right)$ of the SEPIC controlled rectifier for R_Load $=60 \Omega$

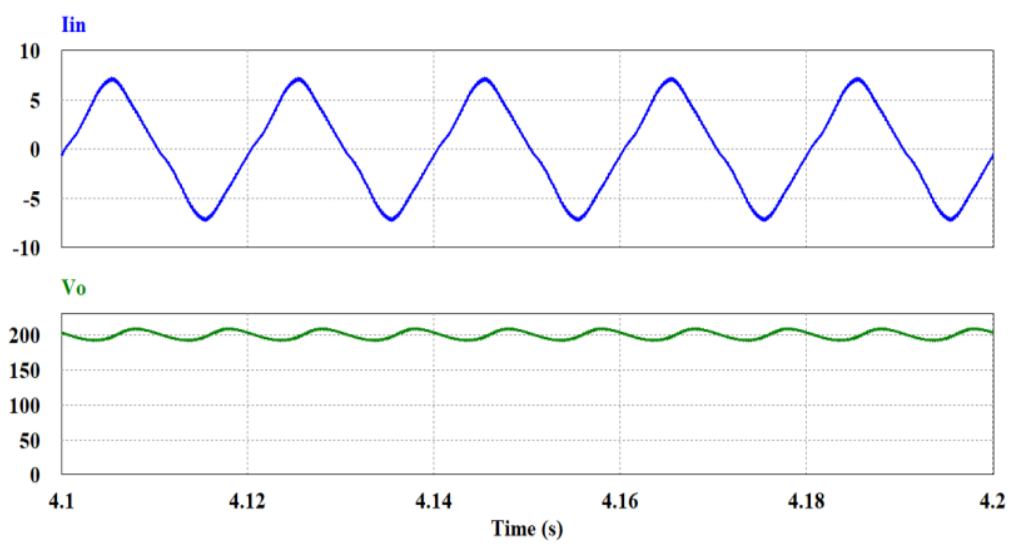

Figure 5. Waveshape of the input current $\left(\mathrm{I}_{\mathrm{in}}\right)$ and the output voltage $\left(\mathrm{V}_{\mathrm{o}}\right)$ of the SEPIC controlled rectifier for R_Load $=100 \Omega$
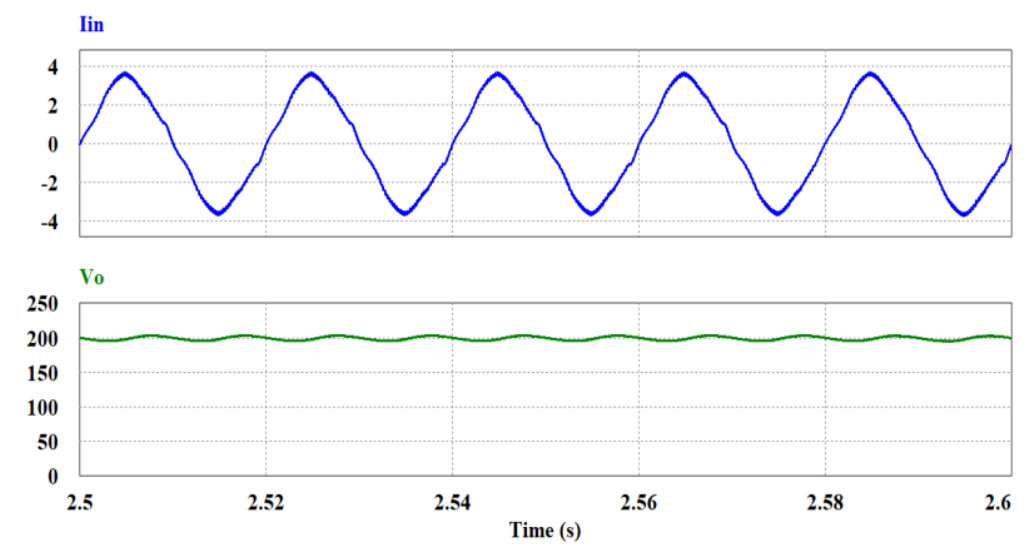

Figure 6. Waveshape of the input current $\left(\mathrm{I}_{\mathrm{in}}\right)$ and the output voltage $\left(\mathrm{V}_{\mathrm{o}}\right)$ of the SEPIC controlled rectifier for R_Load $=200 \Omega$ 


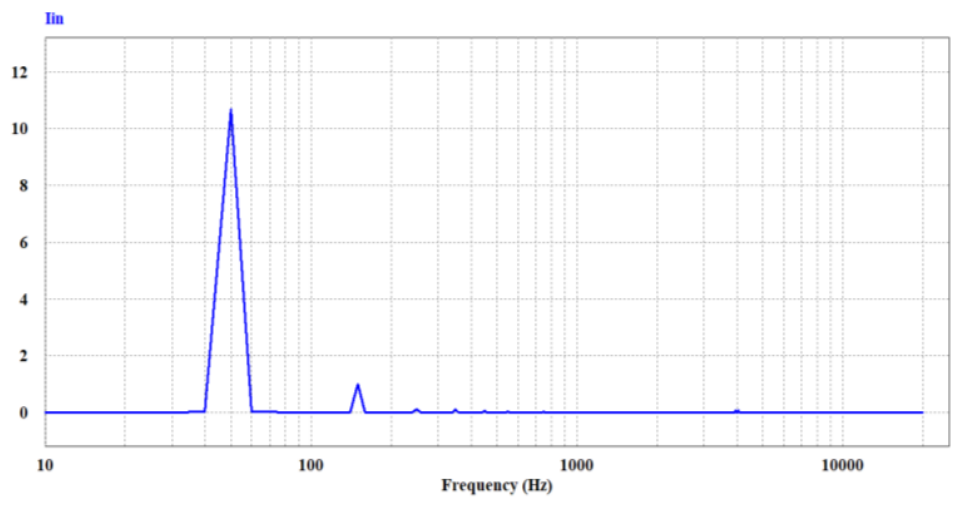

Figure 7. The spectrum of current $I_{\text {in }}$ for the proposed controlled rectifier for R_Load $=60 \Omega$

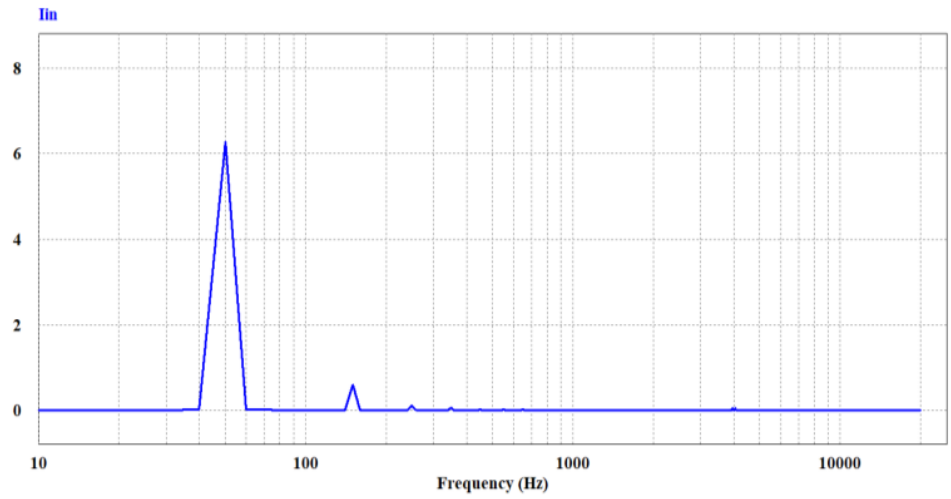

Figure 8 . The spectrum of current $\mathrm{I}_{\text {in }}$ for the proposed controlled rectifier for R_Load $=100 \Omega$

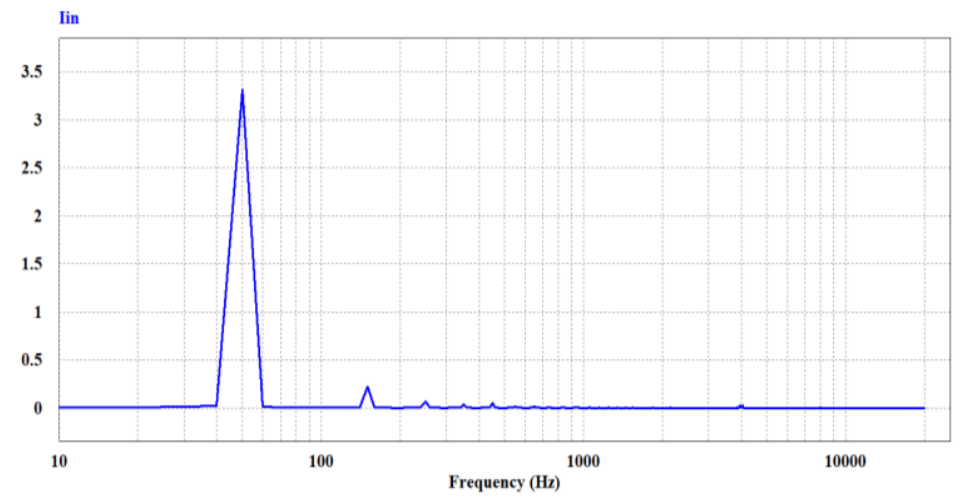

Figure 9. The spectrum of current $\mathrm{I}_{\text {in }}$ for the proposed controlled rectifier for $\mathrm{R} \_$Load $=200 \Omega$

Table 1. Data of THD and power factor for the close-loop SEPIC controlled rectifier

\begin{tabular}{ccc}
\hline Load $(\Omega)$ & THD $(\%)$ & Power Factor \\
\hline 60 & 9.58 & 0.943 \\
100 & 9.89 & 0.984 \\
150 & 8.08 & 0.992 \\
200 & 8.04 & 0.997 \\
250 & 6.01 & 0.9983 \\
300 & 7.28 & 0.997 \\
350 & 7.11 & 0.996 \\
400 & 5.42 & 0.995 \\
450 & 5.08 & 0.994 \\
500 & 5.25 & 0.993 \\
\hline
\end{tabular}




\subsection{Performance comparison}

The performance of the closed loop SEPIC structure has been analyzed considering the open loop SEPIC controlled rectifier having same structure, but without the feedback system. Furthermore, the comparative study of the proposed structure has also been performed considering the conventional system having rectifier with SEPIC DC-DC converter at output end. In both cases, the circuit parameters are kept same to investigate the performance comparison. The performance comparison has been prepared considering the input current THD and power factor at AC side. The outcome of the study is illustrated in Figures 10 and 11.

The bar diagram illustrated in Figure 10 signifies that the THD (\%) of the proposed structure is within the desired range (below 10\%) and compitable to the conventional one for the whole range of load variation. Additionally, the proposed scheme is also comparable to the open loop structure considering THD of input current. The performance comparison associated with input power factor is presented in Figure 11. From this figure it is evident that the power factor of the proposed controlled rectifier is very high and above 94\% in all cases. Furthermore, it is higher than the conventional structure as well as the open loop scheme. Thereby, we can draw a conclusion that the proposed close loop SEPIC controlled rectifier is applicable for a widespread load variation.

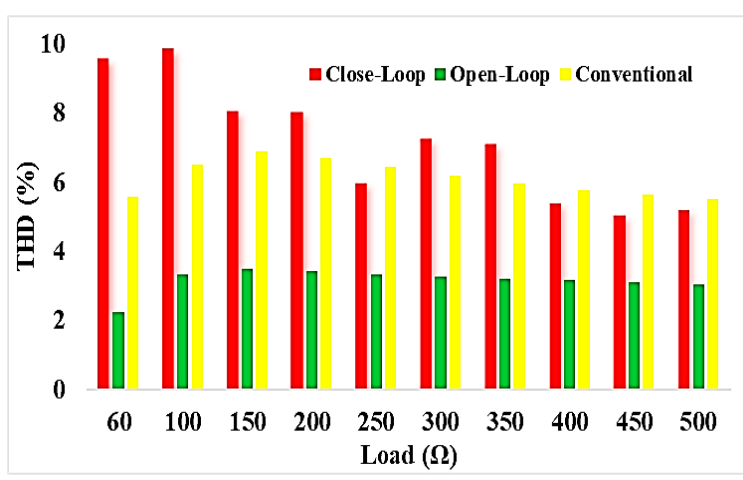

Figure 10. Comparative Scenerio of THD (\%) of the input current

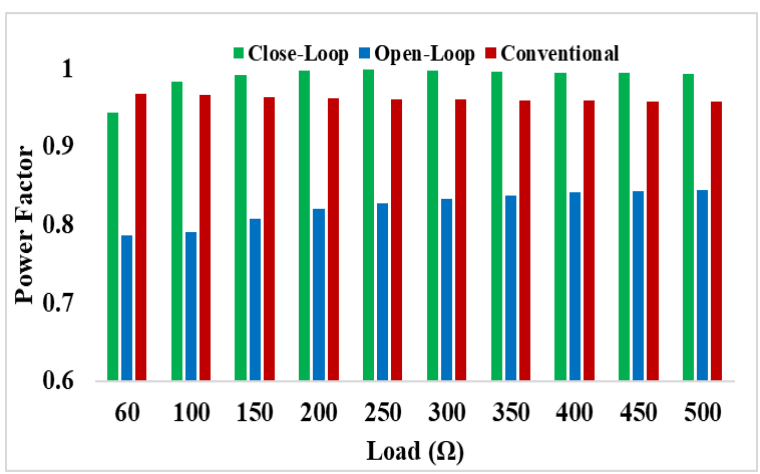

Figure 11. Comparative Scenerio of the input power factor

\section{CONCLUSION}

The structure and operation of a close loop SEPIC controlled rectifier is reported in the paper. Additionally, the performance of the proposed controlled rectifier is also investigated. The fundamental characteristics of the proposed structure is that, the switching mechanism is applied on alternating current. On the contrary, switching is applied on DC side for the conventional AC-DC converter. Satisfactory performances are obtained considering THD and power factor for the close loop construction. The principle benefit of the proposed structure is that, it can supply regulated output voltage maintaining very high-power factor as well as satisfactory THD. Furthermore, single swithching device makes the control structure simple. Moreover, switching loss is reduced as there is only one switch and it helps to rise the overall efficiency of the controlled rectifier. Considering the discussions, it can be summarized that, the close loop SEPIC controlled rectifier is suitable to apply for an extensive range of load.

\section{REFERENCES}

[1] R. Fassler, "Efficiency Regulations: Driving power conversion efficiency designs," IEEE Power Electron. Mag., vol. 4, no. 1, pp. 19-24, 2017.

[2] M. Yilmaz and P. Krein, "Review of charging power levels and infrastructure for plug-in electric and hybrid vehicles and commentary on unidirectional charging," IEEE International Electrical Vehicle Conference, 2012.

[3] S. Komeda and H. Fujita, "A power decoupling control method for an isolated single-phase AC-to-DC converter based on direct AC-to-AC converter topology," IEEE Trans. Power Electron., vol. 33, no. 11, pp. 9691-9698, 2018.

[4] S. Nagaraj, R. Ranihemamalini, and L. Rajaji, "Design and Analysis Of Controllers For High Voltage Gain DC-DC Converter for PV Panel," International Journal of Power Electronics and Drive Systems, vol. 11, no. 2, pp. 594-604, 2020.

[5] M. S. Arifin and M. J. Alam, "Input switched single phase SEPIC controlled rectifier with improved performances," 9th International Conference on Electrical and Computer Engineering (ICECE), pp. 38-41, 2016. 
[6] M. S. Arifin, N. Mohammad, M. I. Khalil, and M. J. Alam, "Input switched closed-loop single phase ĈUK AC to DC converter with improved power quality," International Journal of Power Electronics and Drive Systems, vol. 10, no. 3, pp. 1373-1381, 2019.

[7] M. S. Arifin and M. J. Alam, "Input switched high performance single phase single switch Ćuk AC-DC converter," International Conference on Advances in Electrical Engineering (ICAEE), pp. 226-229, 2015.

[8] V. Rajini, "A novel control scheme to improve the spectral quality of a single-phase bridgeless boost rectifier," International Journal of Power Electronics, vol. 8, no. 1, pp. 52-67, 2016.

[9] M. Ismail Hossain, "Closed loop cuk topology based single phase high performance AC-DC converter," Thesis Department Of Electrical And Electronic Engineering Bangladesh University Of Engineering And Technology, 2013.

[10] M. Shamsul Arifin, "Design and analysis of a single phase single switch cuk and sepic AC-DC converter with improved performance," Thesis Department Of Electrical And Electronic Engineering Bangladesh University Of Engineering And Technology, 2016.

[11] A. H. Abedin et al., "Input switched single phase high performance bridgeless CûK AC-DC converter," IEEE International Conference on Power Electronics, Drives and Energy Systems (PEDES), pp. 1-5, 2012.

[12] M. R. T. Hossain, et al., "Input switched single phase high performance bridgeless AC-DC Zeta converter," IEEE International Conference on Power Electronics, Drives and Energy Systems (PEDES), pp. 1-5, 2012.

[13] A. Shrivastava and B. Singh, "A high power factor and low crest factor Cuk converter for lighting systems," International journal of energy technology and policy, vol. 10, no. 1, pp. 21-35, 2014.

[14] B. Singh, and M. Agrawal., "Analysis and design of single-phase power factor-corrected AC-DC Cuk converter with high-frequency isolation," International Journal of Energy Technology and Policy, vol 4, no 1-2, pp. 161-178, 2006.

[15] M. M. S. Khan et al., "Input switched high performance three phase Buck-Boost controlled rectifier," IEEE International Conference on Industrial Technology (ICIT), pp. 557-562, 2013.

[16] M. A. Kabir, A. H. Abedint, S. Islam, and M. A. Choudhury, "Ćuk topology based single phase AC-DC converter wih low THD and high power factor," 37th Annual Conference of the IEEE Industrial Electronics Society, pp. 1256-1261, 2011.

[17] M. M. S. Khan, M. S. Arifin, M. R. T. Hossain, M. A. Kabir, A. H. Abedin, and M. A. Choudhury, "Input switched single phase buck and buck-boost AC-DC converter with improved power quality," 7th International Conference on Electrical and Computer Engineering, pp. 189-192, 2012.

[18] U. Desai and D. R. Vora, "Modeling and simulation of multi-pulse converter for harmonic diminution," International Conference on Inventive Systems and Control (ICISC), pp. 1-5, 2017.

[19] R. Maurya, P. Agarwal, and S. P. Srivastava, "Performance investigation of Multipulse Converter for Low Voltage High Current applications," IEEE International Conference on Computer Science and Automation Engineering, vol. 1, pp. 211-216, 2011

[20] B. Singh, G. Bhuvaneswari, and V. Garg, "Harmonic mitigation using 12-pulse AC-DC converter in vectorcontrolled induction motor drives," IEEE transactions on power delivery, vol. 21, no. 3, pp. 1483-1492, 2006

[21] B. Singh, S. Gairola, B. N. Singh, A. Chandra, and K. Al-Haddad, "Multipulse AC-DC Converters for Improving Power Quality: A Review," IEEE Transactions on Power Electronics, vol. 23, no. 1, pp. 260-281, 2008.

[22] P. Cortes, D. Bortis, R. Pittini, and J. W. Kolar, "Comparative evaluation of three-phase isolated matrix-type PFC rectifier concepts for high efficiency $380 \mathrm{VDC}$ supplies of future telco and data centers," 16th European Conference on Power Electronics and Applications, pp. 1-10, 2014.

[23] P. Cortes, J. Huber, M. Silva, and J. W. Kolar, "New modulation and control scheme for phase-modular isolated matrix-type three-phase AC/DC converter," 39th Annual Conference of the IEEE Industrial Electronics Society, pp. 4899-4906, 2013.

[24] B. J. D. Vermulst, J. L. Duarte, C. G. E. Wijnands, and E. A. Lomonova, "Quad-Active-Bridge Single-Stage Bidirectional Three-Phase AC-DC Converter With Isolation: Introduction and Optimized Modulation," IEEE Transactions on Power Electronics, vol. 32, no. 4, pp. 2546-2557, 2017.

[25] D. W. Hart, "Power electronics," Tata McGraw-Hill Education, 2011.

[26] S. Li, W. Qi, S. Tan, and S. Y. Hui, "Enhanced Automatic-Power-Decoupling Control Method for Single-Phase AC-to-DC Converters," IEEE Transactions on Power Electronics, vol. 33, no. 2, pp. 1816-1828, 2018.

[27] K. C. Patel, A. V. Sant, and M. H. Gohil, "Shunt active filtering with NARX feedback neural network based reference current generation," International Conference on Power and Embedded Drive Control (ICPEDC), pp. 280-285, 2017.

[28] M. Sharifzadeh et al., "Hybrid SHM-SHE Pulse-Amplitude Modulation for High-Power Four-Leg Inverter," IEEE Transactions on Industrial Electronics, vol. 63, no. 11, pp. 7234-7242, 2016.

[29] H. Vahedi, A. A. Shojaei, L. Dessaint, and K. Al-Haddad, "Reduced DC-Link Voltage Active Power Filter Using Modified PUC5 Converter," IEEE Transactions on Power Electronics, vol. 33, no. 2, pp. 943-947, 2018.

[30] S. S. Yi et al., "Loss minimization DTC electric motor drive system Based on adaptive ANN strategy," International Journal of Power Electronics and Drive Systems (IJPEDS), vol. 11, no. 2, pp. 618-624, 2020.

[31] M. Jannatul ferdous, "Investigation of a diode-capacitor assisted single-phase power factor corrected boost-buck AC-DC converter," Bangladesh University of Engineering and Technology (BUET), 2017.

[32] N. Mohan, "Power electronics: a first course," Wiley, 2011. 